\title{
Vizsgálatok a Látrányi Puszta Természetvédelmi Terület lemezescsápú bogár (Coleoptera: Lamellicornia) faunáján
}

\author{
ROZNER GYÖRGY
}

\author{
Duna-Dráva Nemzeti Park, H-8693 Kisberény, Petőfi u. 1., Hungary
}

ROZNER GY: Investigation on lamellicorn fauna of the Látrányi Puszta Nature Conservation Area (Coleoptera: Lamellicornia)

Abstract: Látrányi Puszta Nature Conservation Area is a fairly small (223 hectares) but extremely interesting part of Somogy County from nature conservational points of view. Regular zoological surveys have been carried out in the area for 4 years that resulted in proving the occurrence of 78 Lamellicornia species. This number represents $40 \%$ of the Hungarian and $54 \%$ of Somogy County's fauna.

Key words:Coleoptera, Lamellicornia, faunistical survey, nature conservation, Hungary

\section{Bevezetés}

A Látrányi puszta Somogy megye északi részén, Külső Somogy területén fekszik. Különlegességét az adja, hogy származását és állapotát tekintve jelentősen eltér a tájegység többi részétől. Kialakulásában az egykori Balaton játszott jelentős szerepet, mely a környék löszdombjai közé homokdünéket épitett, igy a megyében egyedülállóan, túlnyomó részt meszes homok alapkőzet alakult ki. Az évszázadokig tartó gyepgazdálkodás formálta tovább a területet, igy a hullámos felszinen rendkívül változatos élöhely együttes alakulhatott ki, a nyílt homokpuszta gyepektől a láprétekig és vizes élőhelyekig. A terület 1992 óta természetvédelmi oltalom alatt áll.

A terület feltárását 1998- ban kezdtük meg igen szük keretek között, a program az évek során kiteljesedett, így mára átfogó képet kaptunk a terület faunájáról és természeti állapotáról. További célként tüztük ki, hogy a természetvédelem szervezete számára kezelési célokat és módszereket ajánljunk a terület megörzése érdekében.

\section{Anyag és módszer}

A lemezescsápú bogarak gyüjtési sajátságait követve a területen nem törekedtem konkrét mintavételi helyek kijelölésére. A gyüjtési módszerek változatosak voltak, alkalmazkodva az egyes csoportok életmódjához.

A ganajtúró bogarak túlnyomó többsége a Kolláti-legelő északi részéről származik trágyából, mert legeltetés szinte csak itt volt az a vizsgálatok ideje alatt. Boros csapdákat a Birkás-legelö északi részét határoló patak melletti égeres szegélyén és a nyugati oldal erdőszegélyein üzemeltettem. Sok adat származik fühálózásból, ami szinte a teljes területet lefedte, és néhány egyéb gyüjtési módszerekböl, mint talajcsapdázás, lámpázás, autós hálózás. 


\section{Eredmények}

A listán szereplő minden példány a Látrányi Puszta TT területéröl, egyben Látrány községhatárból származik, így a község nevét külön nem tüntettem föl. A faj neve után a közelebbi lelöhely megnevezése következik, majd a gyüjtés dátuma, majd zárójelben a gyüjtési módszer, a fogott darabszám és más gyüjtő esetében annak neve szerepel.

A listában BARAUD (1992) nevezéktanát használom annak ellenére, hogy egyes csoportoknak azóta korszerübbnek számító revíziója is elkészült, mert így az összes lemezescsápú bogarat egységes szellemben tárgyalhatom.

A listában használt rövidítések:

$$
\begin{aligned}
& \text { tcs- talajcsapda } \\
& \text { fh- füháló } \\
& \text { cgy- egyclés } \\
& \text { fcs- fénycsapda } \\
& \text { ah- autós hálózás }
\end{aligned}
$$

Lamellicornia

\section{Lucanidae}

Lucanus cervus (Linnacus, 1758)

Birkás-legelö, 1998. 06. 26. (egy., 1):2001. 06. 24. (Á.L., 1): 2002. 06. 16. (Sz.Cs., tcs, 1): Birkás-legelö, cseres, 2002. 06. 13 - 07. 15. (tcs.,2): Birkás-legelö, 2002. 07. 05 - 15. (bo., 1)

Dorcus parallelepipedus (Linnacus, 1758)

Kolláti-legelö, 1999. 04. 01 - 04. 14. (tcs., 1)

\section{Trogidae}

Trox niger Rossi, 1792

Birkás-legclő, 1999. 03. 31. (bagoly köpetröl,

3): Kolláti-legelö, 2002. 04. 02. (egy., 1):

Trox eversmanni Krynicki, 1832

Kolláti-legelö, 2000. 05. 13. (cgy., 1)

Trox scaber (Linnaeus, 1767)

Kolláti-legelö, 2001. 06. 16. (fcs.,1)

\section{Glaresidae}

Glaresis rufa Erichson, 1848

Birkás-lege1ő, 1999. 07. 12 - 09. 06. (tcs., 1): Kolláti-legelö, 2002. 06. 19. (fcs., 2)

\section{Geotrupidae}

Trypocopris vernalis (Linnaeus, 1758.)

Birkás-legelö, cseres, 2002. 06. 13 - 07. 15

(tcs., 1): Birkás-legelö, 2002. 06, 13 -07. 15. (tcs.,15)

Geotrupes spiniger (Marsham, 1802)

1999.07.25.(tr., 1): 2001. 08. 08. (Á.L., 1):

Kolláti-legelő, 2001. 10. 05. (tr., 1): Birkás-legelő, 2002. 06. 13 - 07. 15 (tcs.,2): Kolláti-legelö, 2002. 10. 04. (tr., 2)

Anoplotrupes stercorosus (Scriba, 1791)

2001. 07. 31. (Á.L., 1)

\author{
ÁL- Ábrahám Levente \\ SzCs- Szinetár Csaba \\ RI- Rozner István \\ PA- Podlussány Attila \\ MO- Merkl Ottó
}

\section{Ochodaeidae}

Ochodaeus chrysomeloides (Schrank, 1781)

2001. 07. 11. (fcs., Á.L., 1): Kolláti-legelö, 2002

06. 19. (fcs., 1)

\section{Aphodiidae}

Aphodius (Colobopterus) erraticus (Linnaeus, 1758) 1999. 07. 25. (tr., 1): Kolláti-legelö, 2000. 05. 13.

(tr., 2): Kolláti-legelő, 2002. 10. 04. (tr., 2)

Aphodius (Teuchestes) fossor (Linnaeus, 1758)

1999. 04. 30. (tr., 3): Kolláti-legelö, 2000. 05. 13. (tr., 1)

Aphodius (Otophorus) haemorrhoidalis

(Linnaeus, 1758)

Kolláti-legelő, 1999 06. 02. (tr., 20): 1999. 04.

30. (tr., 1): Kolláti-legelő, 2000. 05. 13. (tr., 3):

Kolláti-legelö, 2002. 10. 04. (tr., 4)

Aphodius (Plagiogonus) arenarius (Olivier, 1789) 2001. 04. 24. (egy., 1)

Aphodius (Aphodius) fimetarius (Linnaeus, 1758)

Kolláti-legelő, 1999. 03. 31. (tr., 12): 1999. 04.

30. (tr., 2): Kolláti-legelö, 2001. 10. 05. (tr., 1):

Kolláti-legelö, 2002. 04. 02. (cgy., 1): Kolláti-legelö, 2002. 10. 04. (tr., I)

Aphodius (Aphodius) foetens (Fabricius, 1787)

Kolláti-legelö, 2002. 10. 04. (tr., 8)

Aphodius (Acrossus) rufipes (Linnaeus, 1758)

Kolláti-legelő, 2001 10. 05. (egy., R.I., 1)

Aphodius (Acrossus) luridus (Fabricius, 1775)

Kolláti-legelö, 1999. 03. 31. (tr., 2): 1999. 04.

30. (tr., 2): Kolláti-legelő, 2000. 04. 18. (tr., 1):

Kolláti-legelö, 2002. 04.02. (cgy., 2)

Aphodius (Calamostermus) granarius (Linnaeus, 1767)

1998. 04. 24.(tr., 1): 1999. 04. 30. (tr., 3):

Kolláti-legelö, 1999. 05. 22. (tr., 1): Kolláti-legelö, 
1999. 06. 02. (tr., 4): Kolláti-legelö, 2000. 04. 11. (tr.,

2): Kolláti-legelö, 2002. 04. 02. (egy., 1) Aphodius (Agrilinus) ater (Dee Geer, 1774) 1999. 04. 30. (tr., 1)

Aphodius (Planolinus) uliginosus (Hardy, 1847) Kolláti-legelö, 2002. 04. 02. (egy., 1):

Aphodius (Acanthobodilus) immundus Creutzer, 1799 Kolláti-legelő, 1999. 06. 02. (tr., 4): Kolláti-legelő, 2001. 06. 16. (fcs., 3): 2001. 06. 25. (Á.L., 1): 2001. 07. 11. (fcs., Á.L., 1): Kolláti-legelő, 2002. 06. 19. (fcs., 4): Kolláti-legelö, 2002. 10. 04. (tr., 1)

Aphodius (Agrilinus) scybalarius (Fabricius, 1781) Kolláti-legelö, 2001. 10 .05. (tr., 9): Kolláti-legelö, 2001. 10. 05. (egy., R.I., 2): Kolláti-legelö, 2002. 06. 19. (fcs., 1): Kolláti-legelö, 2002. 10. 04. (tr., 5) Aphodius (Agrilinus) sordidus (Fabricius, 1775) Kolláti-lege1ő, 1999. 09. 07. (tr., 1): Kolláti-legelö, 2002. 10. 04. (tr., 1)

Aphodius (Bodilus) lugens Creutzer, 1799

Kolláti-legelö, 2001. 06. 16 (fcs., 7): 2001. 06. 25. (Á.L., 4): Kolláti-legelő, 2002. 06. 19. (fcs., 1) Aphodius (Nialus) varians Duftschmid, 1805 1999. 04. 30. (tr., 6): Kolláti-legelő, 1999. 06. 02. (tr., 1): 1999. 07. 25. (tr., 1): Kolláti-legelö, 2000. 04. 18. (tr., 5): Birkás-legelö, 2001. 04. 26. (egy., R.I., 1): Kolláti-legelö, 2001. 06. 16.(fcs., 10): Kolláti-legclő, 2002. 06. 19. (fcs., 1)

Aphodius (Liothorax) niger (Panzer, 1797)

Kolláti-legelö, 2002. 04. 26. (egy., 1)

Aphodius (Chilothorax) distinctus (O.F. Müller, 1776)

Kolláti-legelö, 1999. 03. 31. (tr., 3): Kolláti-legelő, 1999. 05. 22. (tr., 1): Kolláti-lcgelő, 2000. 04. 11. (tr., 3): Kolláti-legelö, 2001. 03. 10. (tr., 3): Kollátilegelö, 2001. 10. 05. (tr., 1): Kolláti-legelő, 2002. 04. 02. (egy., 1): Kolláti-legelö, 2002. 10. 04. (tr., 2)

Aphodius (Chilothorax) melanostictus W. Smidt, 1840. Kolláti-legelö, 2002. 04. 02. (egy., 5)

Aphodius (Nimbus) contaminatus (Herbst, 1783) Kolláti-legelö, 2002. 10. 04. (tr., 1)

Aphodius (Melinopterus) prodromus (Brahm, 1790) Kolláti-legclö, 1999. 03 .05. (tr., 8): Kolláti-legelö, 1999. 03. 31. (tr., 7): 1999. 04. 30. (tr., 3)

Aphodius (Melinopterus) sphacelatus (Panzer, 1798)

Kolláti-legclö, 1999. 03. 31. (tr., 2)

Aphodius (Melinopterns) consputus (Creutzer, 1799)

Kolláti-legclö, 1999. 03. 05. (tr., 1): Kolláti-legclö, 2001. 03.10. (tr., 1): Kolláti-legelö, 2001. 10.05. (tr., 2): Kolláti-lcgelő, 2001. 10. 05. (egy., R.I., 1): Kolláti-lcgelö, 2002. 10. 04. (tr., 3)

Aphodius (Eurodalus) coenosus (Panzer, 1798)

1999. 04. 30. (tr., 1): Kolláti-lcgelö, 2000. 05. 13.

(tr., 4): Kolláti-legelö, 2002. 04. 02. (tr., 1)

Aphodius(Esymus) pusillus (Herbst, 1789)

1999. 04. 30. (tr., 1)

Aphodius (Phalacronothus) biguttatus Germar, 1824

Kolláti-legelö, 1999. 05. 22. (tr., 1): Birkás-lege-

lö, 1999. 04. 14. (fh., 1)

Aphodius (Sigorus) porcus (Fabricius, 1792)

Kolláti-legelö, 2001. 10. 05. (tr., 2): Kolláti-leg- elő, 2001. 10. 05. (cgy., R.I., 1): Kolláti-legelő, 2002. 10. 04. (tr., 2)

Oxyomus silvestris (Scopoli, 1763)

Kolláti-legelö, 1999. 03. 31. (tr., 11): Kollátilegelö, 2002. 10. 04. (tr., 2)

Diastictus vulneratus (Sturm, 1805)

Kolláti-legelö, 1999. 04. 5-05. 22. (tcs., 1)

Pleurophorus caesus Creutzer, 1796

1998. 04. 24. (tr., 1): 1998. 04. 24-05. 15. (tcs., 1): Kolláti-legelö, 2001. 06. 16. (fcs., 9): 2001. 07. 11. (fcs., Á.L., 2): Kolláti-legelő, 2002. 06. 19. (fcs., 6)

Rhyssemus germanus (Linnacus, 1767)

1998. 04. 24. (tr., 1): 1998. 04. 24-05. 15. (tcs., 1): 2002. 06. 16. (tcs., Sz.Cs.,1)

\section{Scarabaeidae}

Copris lunaris (Linnaeus, 1758)

1999. 07. 12. (tr., 1): Kolláti-legelö, 2001. 10. 05. (egy., R.I., 1): Kolláti-legelö, 2002. 10. 04. (tr., 2)

Oniticellus (Euniticellus) fulvus (Goeze, 1777)

Kolláti-legelö, 1999. 05. 22-06. 24. (tcs., 1): 1999. 06. 02. (tr., 1): Kolláti-legclö, 2001 10. 05. (tr., 1): Kolláti-legelö, 2001. 10. 05. (egy., R.I., 1)

Caccobius Schreberi Linnaeus, 1767

1999. 04. 30. (tr., 3): 1999. 07. 25. (tr., 3):

Kolláti-legelö, 1999. 06. 02. (tr., 1)

Onthophagus (Onthophagus) toumus (Schreber, 1759)

1999. 04. 30. (tr., 1): Birkás-legelő, (5.sz. terület), 2001. 07. 05. (fh., M.O., 1): 2001. 09. 10. (tr., 2): Kolláti-legelő, 2001. 10. 05. (tr., 1): Kolláti-legelö, 2001. 10. 05. (egy., R.I., 1): ): Birkás-legelő, (5.sz. terület), 2002. 05. 04. (fh., M.O., 1): Kolláti-legelö, 2002. 10. 04. (tr., 2)

Onthophagus (Furconthophagus) furcatus (Fabricius, 1781)

1998. 04. 24-05. 15. (tcs., 3): 2001. 04. 18. (tr., 1): Kolláti-legelö, 2001. 10. 05. (tr., 2)

Onthophagus (Palaeonthophagus) vitulus

(Fabricius, 1776)

1999. 07. 12. (tr., 3)

Onthophagus (Palaeonthophagus) verticicornis

(Laicharting, 1781.)

Birkás-legelö, akácos, 2002. 06. 13-07. 15

(tcs., 1): Birkás-lcgelö, 2002. 06. 13-07. 15 (tcs.,2)

Onthophagus (Palaeonthophagus) semicornis

(Panzer, 1798)

Birkás-legelö, 1999. 04. 25-05. 22. (tcs., 1)

Onthophagus (Palaeonthophagus) ovatus

(Linnacus, 1767)

2001. 04. 18.(tr., 3): Birkás-legelö, 2002.04. 26 (fh., P.A., 1): 2002. 06. 16. (tcs., Sz.Cs.,1): Birkás-legelö, akácos, 2002. 06. 13-07. 15 (tcs.,1): Birkás-legclö, 2002. 06. 13-07. 15 (tcs.,1)

Onthophagus (Palaeonthophagus) ruficapillus (Brulle, 1832)

1999. 04. 30. (tr., 1): Kolláti-legelö, 1999. 03. 31.(tr., 6): 2001.04.18.(tr., 2): Kolláti-legelö, 2001. 10 .05. (tr., 1): Kolláti-legelö, 2002. 04. 02. (egy., 3) 


\section{Onthophagus (Palaeonthophagus) nuchicornis \\ (Linnaeus, 1758) \\ Kolláti-legelö, 2000. 05. 13. (tr., 1) \\ Onthophagus (Palaeonthophagus) fracticornis}

(Preyssler, 1790)

Kolláti-lcgelő, 2001. 03. 10. (tr., 3): Kolláti-legelö, 2001. 10. 05. (tr., 2): Kolláti-legelö, 2001, 10.05. (egy., R.I., 2): Kolláti-legelő, 2002. 04. 02. (egy., 3): Kolláti-legelö, 2002. 10, 04. (tr., 1)

Onthophagus (Palaeonthophagus) gibbulus (Pallas, 1781)

Kolláti-lcgclô, 1999. 03. 31. (tr., 2): Birkás-lege-

lö, 1999.03.31.(fh., 1)

Onthophagus (Palaeonthophagus) coenobita

(Herbst, 1783)

1999. 04. 30 .(tr., 1): Kolláti-legelő, 1999. 03.31.

(tr., 1): Birkás-legelö, akácos, 2002. 06. 13 - 07. 15.

(tcs., 1): Birkás-legelö, cseres, 2002. 06. 13 - 07. 15. (tcs.,2) Onthophagus (Palaeonthophagus) vacca

(Linnaeus, 1767) 1999. 04. 30. (tr., 1): 1999, 07. 25. (tr., 1):

Kolláti-legelő, 1999. 03. 31. (tr., 1)

\section{Melolonthidae}

Anoxia (s.str.) pilosa (Fabricius, 1792)

1999. 07. 16. (Á.L., 3): Kolláti-legelö, 2000. 06.

04. (egy., 1) ): Kolláti-legelö, 2001. 06. 16. (fcs., 13):

Kolláti-legelö, 2002. 06. 19. (fcs., 3)

Polyphylla (Polyphylla) fullo (Linnaeus, 1758)

1999. 07. 16. (A.L., 2): Kolláti-legelő, 2001. 06.

16. (fcs.,3): 2001 .06. 24. (Á.L., 4)

Melolontha melolontha (Linnacus, 1758)

legelö, 1998. 04. 24. (egy., 1): 2001. 04. 12.

(egy., 1): 2002. 04. 26 .(cgy., 1)

Serica (s.str.) brunnea (Linnacus, 1758)

2001. 07. 11. (fcs., Á.L., 2): 2002. 06. 16

(Sz.Cs., tcs, 3): Birkás-legelö, akácos, 2002. 06. 13 -

07. 15. (tcs., 1): Birkás-legelő, fenyves, 2002. 06. 13 -

07. 15. (tcs.,2)

Maladera (s.str.) holosericea (Scopoli, 1772)

1998. 04. 24 - 05. 15. (tcs., 2): 1999. 06. 02.

(Á.L., 2): Kolláti-legelö, 1999. 04. 15 - 05. 22. (tcs.,

3): 2000. 05. 13. ( K.E., 1): 2002. 06. 16. (Sz.Cs., tcs, 1)

Homaloplia (s.str.) ruricola (Fabricius, 1775)

Birkás-legelö, 1999. 07. 12. (egy., 1): Birkás-le-

gelő, 2001. 06. 26. (cgy., R.I., 7): 2002. 06. 16. (tcs., Sz.Cs., 1)

Homaloplia (Acarina) spiraeae (Pallas, 1773)

Birkás-legelö, 1999. 05. 24. (fh., 7): Birkás-lege-

lö, 2000. 06. 03. (cgy., R.1., 3): 2002. 06. 16.(tcs.,

Sz.Cs., 1)

Amphimallon solstitiale (Linnaeus, 1758)

1999.06.29.(Á.L., 1): Kolláti-legelő, 2001. 06.

16. (fcs., 3): Kolláti-legelö, 2002. 06. 19. (fcs., 1)
Hoplia (Decamera) farinosa (Linnaeus, 1761), (=Hoplia philanthus (Fucsslin, 1775))

1998. 06. 22. (egy., 4): Birkás-legclő, 2000. 06.

04. (cgy., 6): Kolláti-legelő, 2000. 06. 04.(egy., 3):

Birkás-legelö, 2001. 06. 6. (egy., R.I., 1): 2002. 06.

16. (Sz.Cs., tcs, 14)

Hoplia hungarica Burmcister, 1844

2002. 06. 16. (tcs., Sz.Cs.,2)

\section{Rutelidae}

Anomala (s.str) dubia (Scopoli, 1763)

1999. 07. 12. (fh., 2)

Anomala (s.str) vitis (Fabricius, 1775)

Kolláti-legelő, 2002. 06. 19. (fcs., 1)

Phyllopherta horticola (Linnaeus, 1758)

Birkás-legelö, 2000. 05. 13. (egy., 1)

Chaetopteroplia segetum (Herbst, 1783)

1998.06.22.(fh., 1): Birkás-legelö, 1999. 06. 22. (fh., 11): 1999. 05. 30. (Á.L., 1): Kolláti-legelő, 2000. 06. 04 .(egy., 1): Birkás-legelö, 2001.06.1 4. (egy., 2)

\section{Cetoniidae}

Tropinota hirta (Poda, 1761)

1998. 04. 24. (cgy., 1): 1998. 05. 15. (fh., 2): 1999. 04. 15. (Á.L., 1) Birkás-legelö, 1999. 04. 25 05. 22. (tcs., 2): 2000. 04. 13. (Á.L., 1): Kolláti-legelö, 2000. 06. 03. (egy., R.I., 1): Birkás-legelö, (5.sz. terület), 2001. 07.05. (fh., M.O., 1): Kolláti-legelö, 2002. 04. 02. (cgy., 1): Birkás-lcgelö, 2002. 04. 16. (R.I., egy., 1): Birkás-legelő, 2002. 04. 26. (egy., 1): Nyircs-legelö, 2002. 04. 26. (R.I., 2): 2002. 06. 16. (Sz.Cs., tcs, 1)

Oxythyrea funesta (Poda, 1761)

Birkás-legelö, 1999. 05. 24. (egy., 1): 1999. 06.

02. (egy., 1)

Cetonia aurata aurata (Linnacus, 1758)

Birkás-legelő, 1999. 05. 24. (egy., 1): Birkás-legclö, 1999. 06. 02. (cgy., 1): 2000. 05. 13. (egy., 1): Kolláti-legelö, 2001. 10. 05. (cgy., R.I., 1)

Cetonischema aeruginosa (Drury, 1770)

Birkás-legelő, 2002. 07. 05 - 15. (Bo., 1)

Netocia (Potosia) cuprea metallica (Herbst, 1782)

Birkás-legelö, 2002. 07. 05 - 15. (bo., 1)

Netocia (Potosia) cuprea obscura (Andersch, 1797)

Kolláti-legelö, 2001. 06. 16. (cgy., 4): Birkás-legelö, 2002. 07. 05 - 15. (bo., 8)

Netocia (Netocia) hungarica (Herbst, 1792)

Birkás-legelö, 2000. 06. 04 (cgy., 1): 2002. 05.

07. (egy., 1)

Valgus hemipterus (Linnacus, 1758)

1998. 04. 24. (cgy., 1): Birkás-lcgelö, 1999. 05.

22 - 06. 24. (tcs., 2) 
A terület az elözetes várakozásnak megfelelően igen gazdagnak bizonyult. Annak ellenére, hogy a terület nagyon kicsi és túlnyomórészt gyepterület, hiányoznak a fajgazdag természetes erdők, 78 lemezescsápú bogár fajt sikerült kimutatni. A terület jellegéből adódóan különösen a ganajtúró fauna gazdag, szinte minden domb és síkvidéki faj megtalálható, melyekböl a kimondottan homokpusztákhoz kötődő fajok fontosak, hiszen ezek a Dunántúlon ritkábbak.

A területről Somogy megye faunáját tekintve két új faj, az Aphodius porcus és az Aphodius aranarius került elö. Védett fajok közül a Lucanus cervus-t, a Dorcus paralellepipedus-t és a Cetonischema aeruginosa-t és a Netocia hungarica-t sikerült kimutatni.

A ritkább fajok közül érdemes még megemlíteni az Aphodius fossor-t, az A. ater-t és az A.contaminátus-t, melyek sehol sem gyakoriak, illetve a homokterületekhez kötődő Glaresis rufa-t és az Ochodaeus chrysomeloides-t.

\section{Természetvédelmi vonatkozások}

A Látrányi puszta változatos és többnyire természet közeli állapotban fennmaradt élőhelyeinek lemezescsápú bogár faunája gazdag, mind a fajszámot, mind a fajösszetételt tekintve. A fauna megőrzésének elsődleges feltétele, hogy az értékes élőhelyek jó állapotát megőrizzük és lehetőség szerint a leromlókat feljavítsuk.

A terület kicsinysége és kedvezötlen tulajdonszerkezete, a müvelés hiánya miatt, az élöhelyek megörzése csak aktív beavatkozással, kezeléssel, néhány területen pedig élöhely rekonstrukcióval oldható meg.

A ganajtúró fauna megörzése szempontjából elsődleges fontosságú a gyeptrerületek legeltetéses hasznosítása. A legolcsóbb kezelési módszer lehetne, amely segíthetne a legelök általános természeti állapotának fenntartásában is. Sajnos az állatállomány drasztikus csökkenése és a rendezetlen tulajdonviszonyok jelenleg ezzel ellentétesen hatnak.

Sok értékes faj megörzését segítené, ha a területen található ültetvény jellegü tájidegen faállományokat lecserélhetnénk őshonos tölgyes, cseres erdőkre.

\section{Köszönetnyilvánítás}

Köszönetemet fejezem ki a programban résztvevő kutatóknak, Ábrahám Leventének, Merkl Ottónak, Podlussány Attilának, Rozner Istvánnak, Szinetár Csabának az általuk gyüjtött anyag rendelkezésemre bocsátásáért. Köszönet illeti Lökkös Andort, aki a terepi munkában is segítségemre volt.

\section{Irodalom}

Baraud J. 1992: Coléoptéres Scarabacoidae D'Europe - Fauna de France pp. 1-856.

ENDRŐDI S. 1956: Lemezescsápú Bogarak- Lamellicornia - Magyarország állatvilága (Fauna Hungariac) 9(4): $1-188$.

ROZNER GY. 2001: Somogy megye dögbogár, sutabogár és lemezescsápú bogár faunája (Colcoptera: Silphidae, Histeridac, Lamellicornia) - Natura Somogyiensis 1: 161-167. 


\section{Investigation on lamellicorn fauna of the Látrányi Puszta Nature Conservation Area (Coleoptera: Lamellicornia)}

\section{GYÖRGY ROZNER}

The investigated area has been under protection since 1992. Here, in an extremely mosaic arrangement, a rather diverse surface can be found: sandy grasslands developed on the calciferous sand, different types of marshlands and marshy meadows, just as well as various forest vegetation. The research work focused partly on surveying the present condition of the area, and partly on estimating the necessary steps demanded by the future.

Considering the fauna of Somogy County, two new species were recorded in the area such as: Aphodius porcus and Aphodius aranarius. Of the protected species Lucanus cervus, Dorcus paralellepepedus and Cetonischema aeruginosa were found. 